\title{
Retro-oesophageal right subclavian artery in association with thyroid ima artery: a case report, clinical impact and review of the literature
}

\author{
K. Natsis ${ }^{1}$, N. Lazaridis², A. Gkiouliava², M. Didagelos², M. Piagkou ${ }^{3}$ \\ ${ }^{1}$ Department of Anatomy, Medical School, Aristotle University, Thessaloniki, Greece \\ ${ }^{2}$ Aristotle University of Thessaloniki, Greece \\ ${ }^{3}$ National and Kapodistrian University of Athens, Greece
}

[Received: 11 April 2015; Accepted: 21 June 2015]

\begin{abstract}
A 37-year-old female Caucasian cadaver with an aberrant right subclavian artery extending from the left side of the aortic arch and following a retro-oesophageal course is presented. A non-recurrent right laryngeal nerve and a thyroid ima artery arising from the lower part of the middle third of the right common carotid artery coexisted. The brachiocephalic trunk was absent, while both common carotid arteries and left subclavian artery followed their normal course. The aim of the current study is to highlight the clinical impact of the above abnormalities providing useful and practically applicable knowledge to interventional clinicians, thoracic and neck surgeons, since the vast majority of documented cases with an arteria lusoria are clinically silent and in most cases discovered incidentally. Clinical manifestations such as dysphagia, chronic cough, and acute ischaemia to the right upper limb may occur, leading to misinterpretation in radiographic examination and complications during neck and thoracic surgery. Review of the literature was also performed and the embryological background of the aberration is highlighted. (Folia Morphol 2016; 74, 1: 130-135)
\end{abstract}

Key words: aortic arch variations, arteria lusoria, non-recurrent laryngeal nerve

\section{INTRODUCTION}

Numerous variations in the branching pattern of the human aortic arch exist [39, 41, 50]. "Normal" or "classic" type gives rise to three branches: (a) the brachiocephalic trunk (BT) as the largest branch that gives off the right subclavian artery (RSA) and the right common carotid artery (RCCA), (b) the left common carotid artery (LCCA) and (c) the left subclavian artery (LSA) [23].

This pattern referred to as "type $A$ " according to Adachi [2] is detected in a variable incidence of $64.9-94.3 \%[4,50]$ among several populations, with higher incidences in Japanese (94.3\%) [52], Indians (91.4\%) [51] and Caucasians (83\%) [50]. Following the systematic classification of the variability of the aortic arch branches [52], an aberrant RSA may occasionally arise next to a normally positioned LSA, as the last branch of the aortic arch, in $0.16-25 \%$ of the individuals $[9,50]$. Hunald first described the aberrant vessel on a necropsy in 1735 and Bayford coined the term 'dysphagia lusoria' in 1761, after discovering a retro-oesophageal RSA — RERSA (arteria lusoria) compressing the oesophagus in a 62-year-old woman who suffered from swallowing difficulty and eventually died of emaciation [5]. The BT absence and the arteria lusoria presence are the findings used to identify the non-recurrent right laryngeal nerve (NRLN) [70]. Occasionally, a thin anomalous feeding vessel, the thyroid ima artery (IMA) or artery of Neu-

Address for correspondence: K. Natsis, MD, PhD, Department of Anatomy, Medical School, Aristotle University of Thessaloniki, P.O. Box: 300, 54124 Thessaloniki, Greece, e-mail: natsis@med.auth.gr 


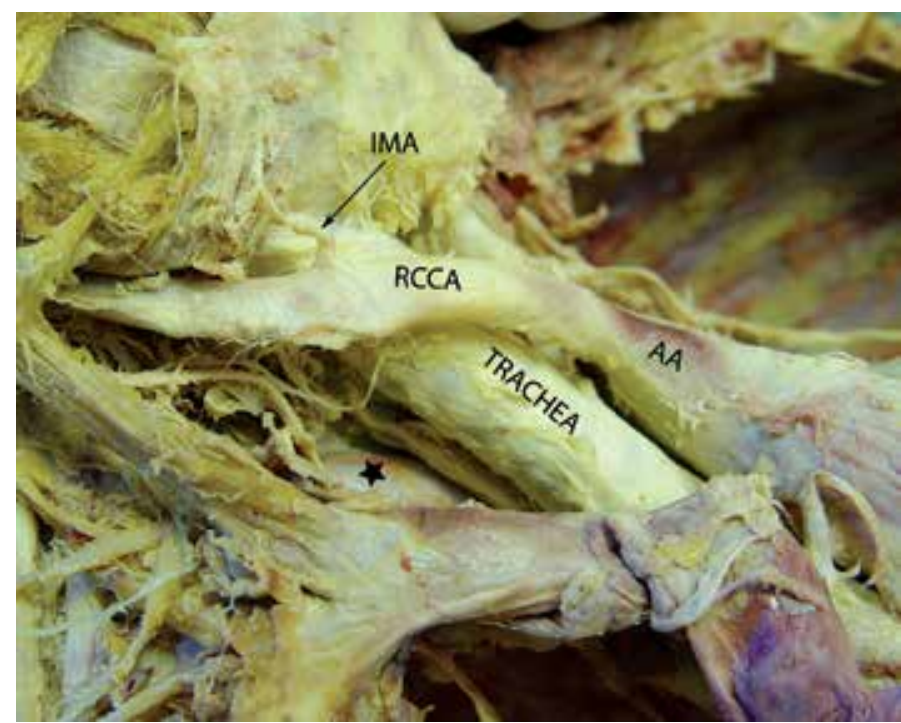

Figure 1. View of the aortic arch and its branches showing the retro-oesophageal right subclavian artery (asterisk); AA — aortic arch; RCCA — right common carotid artery; IMA — thyroid ima artery.

bauer ascending to the thyroid gland is detected in 1.5-12.2\% according to Faller and Scharer (1947) as cited by Krudy et al. [37]. This inconstant artery, usually detected on the right side, may be given off from the BT $(0.5-3 \%)[18,43]$, the RCCA $(0.5-1 \%)$ $[41,43]$, the aortic arch $(0.1-2.22 \%)[35,43]$, the internal thoracic artery, the pericardiophrenic artery, the subclavian artery, the thyrocervical trunk, the inferior thyroid artery or the transverse scapular artery. An IMA replacing the left inferior thyroid artery [42] or an IMA arising from the BT associated with bilateral absence of the inferior thyroid arteries were detected [73]. In both cases the right and left recurrent laryngeal nerves (RLNs) had a typical course. Locating IMA is of paramount importance during neck surgery due to the high risk of iatrogenic injury to the artery and during parathyroid arteriography when detecting adenomas or other gland lesions [37]. In the present study we report a rare case of a RERSA associated with an IMA arising from the RCCA and a right NRLN. Moreover, the embryological background of the coexistent variations is highlighted.

\section{CASE REPORT}

During a routine dissection of a 37-year-old formalin embalmed female Caucasian cadaver at the Department of Anatomy (Medical School of the Aristotle University of Thessaloniki), a very rare aberration of the aortic arch was detected. After the careful dissection of the anterior part of the neck and the thoracic cavity, 4 branches of the aortic arch were identified (proximal to distal): the RCCA giving rise to an IMA from the lower part of its middle third (below the CCA bifurcation), the LCCA, the LSCA and a RERSA as the last branch (Figs. 1, 2). Consequently no BT was observed. The IMA after its emersion, passed inwards and directly upwards, supplying the right lobe and the lower part of the isthmus of the thyroid gland. The vessel had 1 bifurcation and multiple terminal branches. The RERSA coursed horizontally between the oesophagus and the vertebral column, on its way to the right upper limb. The perimeter of the RERSA diminished gradually as the artery coursed towards the right side of the neck. The right recurrent laryngeal nerve branched directly from the vagus nerve, while the contralateral nerve (left RLN) appeared to loop around the aortic arch normally. The lumen of all great vessels was free of any aneurysmal dilatation. Except for the RERSA, both CCAs and LSA followed their typical course to the neck, adopting their usual origin and distribution pattern. After a detailed investigation of the cadaver's medical records, no relevant clinical manifestations, such as right upper extremity ischaemia or dysphagia lusoria were retrieved. The thoracic duct followed the classic course and drained normally into the jugular-subclavian junction. Trachea and oesophagus had normal structure and position. No malformations or anomalies were observed in the rest of the thoracic and abdominal organs. The cause of death was unrelated to the encountered findings. 


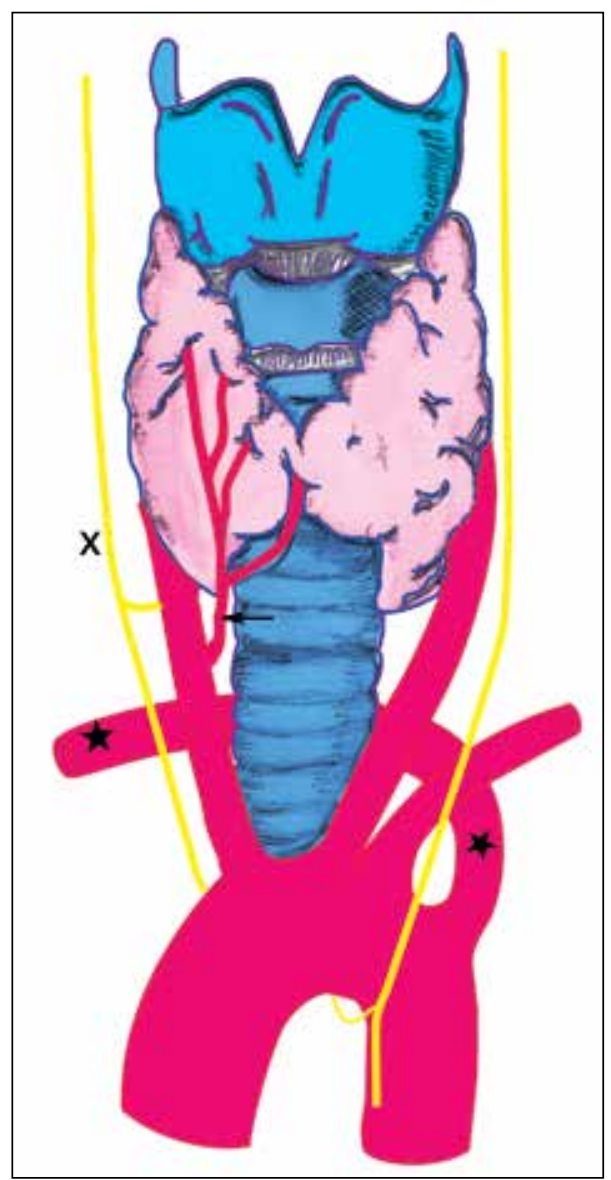

Figure 2. A scheme presenting the retro-oesophageal right subclavian artery (asterisk) and the thyroid ima artery (arrow). All branches of the aortic branch are demonstrated; $\mathrm{X}$ - vagus nerve.

\section{DISCUSSION}

A plethora of classifications of the human aortic arch branches has been reported. Most likely these variations appear due to altered development of certain arteries of the branchial arch [7, 68]. Formation of an aberrant RSA is the result of the $4^{\text {th }}$ vascular arch degeneration along with the dorsal aorta, while the $7^{\text {th }}$ intersegmental artery remains attached to the descending aorta [20]. The persistent intersegmental artery will eventually become the RERSA or arteria lusoria in $80-84 \%$ of the cases, or the aberrant RSA passes behind the trachea in 12.7-15\% or in front of the trachea in 4.2-5\% $[5,18]$. The Kommerell's aortic diverticulum, a remnant of the distal right aortic arch may be detected at the RSA origin. As regards the morphometric details, the diameter of the RRSA is usually greater at the proximal than the distal part [20], while its wall is thinner than that of normal arteries of the same diameter [3].
The occurrence of the RERSA varies widely between $0.8 \%$ and $37 \%$ among various populations, the higher figure corresponds to the incidence in Down syndrome patients with congenital heart disease [9, $29,41,58,70]$. The higher reported incidence with a wide range of $2.46-9.7 \%$ were found in African Americans by Bean (1905) and Loth (1912) as cited by De Garis et al. [21], followed by Germans (4\%) [55], Japanese (3.95\%) [48] and South Africans (1.4\%) [17]. Contrariwise, a very low incidence $(0.30 \%)$ was detected in a European population [1]. The arteria lusoria is associated with other congenital anomalies, such as the formation of a bicarotid trunk (BCT), an aortic coarctation, a replaced right or left vertebral artery, a persistent left superior vena cava [72], a ventricular septal defect, the tetralogy of Fallot [44], pulmonary atresia and major aortico-pulmonary collateral arteries [40]. Reinshagen et al. [55] emphasized that the arteria lusoria was present in $14.8 \%$ of patients with BCT, while patients with classic anatomy of the neck vessels presented the artery in $2.1 \%$. Natsis et al. [49] highlighted that the coexistence of arteria lusoria and BCT appears in up to $2.78 \%$ in Caucasians. Moreover, higher incidence of arteria lusoria has been reported in patients with Down syndrome (12-37\%) $[16,29,57,74]$, Edwards and DiGeorge syndrome and congenital heart disease $[45,63]$. The artery may also coexist with long gap oesophageal atresia and trachea-oesophageal fistula in neonates [13].

Abnormal aortic arch development is related with variation in the course of the RLN [17]. Arteria lusoria is usually associated with right NRLN, due to the fact that during foetal development, the vessel fails to drag the nerve caudally when the heart descends and neck elongates [3, 22]. Simmons et al. [61] and Tateda et al. [65] reported a RERSA associated with a right NRLN. Tartaglia et al. [64] and Wang et al. [69] found an arteria lusoria in coexistence with a right NRLN in $0.4 \%$ of their sample and Toniato et al. [67] in $0.5 \%$. De Garis et al. [21] mentioned the presence of a right NRLN in all cases of RRSA, except of one specimen where the RLN followed a recurrent course under the inferior thyroid artery. The right NRLN appears in $0.3-1.6 \%$ [66], while the left NRLN is extremely rare with an incidence of up to $0.04 \%$ [32]. The atypical course of the recurrent laryngeal nerve, usually on the right side is clinically important during thyroidectomy and parathyroidectomy, where the nerve cannot be identified at the lower pole of the thyroid gland and may be injured during the procedure [67]. Hence, the 
Table 1. Literature overview pertaining to a thyroid ima artery (IMA) in combination with a retro-oesophageal right subclavian artery

\begin{tabular}{|c|c|c|c|c|c|c|c|}
\hline Study & Year & Gender & Sample & $\begin{array}{c}\text { Race/ } \\
\text { /Material }\end{array}$ & IMA/Origin & RSA Course & RLN \\
\hline $\begin{array}{l}\text { Hammer and Meis } \\
\text { [31] }\end{array}$ & 1941 & Female & Case report & $\begin{array}{c}\text { African American/ } \\
\text { /Cadaver }\end{array}$ & Thymica/LCCA & $\begin{array}{c}\text { Retro- } \\
\text {-oesophageal }\end{array}$ & NRLN \\
\hline $\begin{array}{l}\text { Hammer and Meis } \\
{[31]^{*}}\end{array}$ & 1941 & Female & Case report & $\begin{array}{l}\text { Caucasian/ } \\
\text { /Cadaver }\end{array}$ & IMA/RCCA & $\begin{array}{c}\text { Retro- } \\
\text {-oesophageal }\end{array}$ & RLN under IMA \\
\hline $\begin{array}{l}\text { Simmons et al. } \\
{[61]^{* *}}\end{array}$ & 1987 & Female & Case report & $\begin{array}{l}\text { Not mentioned/ } \\
\text { /Angiography }\end{array}$ & IMA/RCCA & $\begin{array}{c}\text { Retro- } \\
\text {-oesophageal }\end{array}$ & NRLN \\
\hline $\begin{array}{l}\text { Loukas et al. } \\
\text { [42] }\end{array}$ & 2006 & Male & Case report & $\begin{array}{l}\text { Not mentioned/ } \\
\text { /Cadaver }\end{array}$ & $\begin{array}{l}\text { IMA/Common } \\
\text { trunk with the RVA }\end{array}$ & Retrotracheal & RLN \\
\hline Present case & 2015 & Female & Case report & $\begin{array}{l}\text { Caucasian/ } \\
\text { /Cadaver }\end{array}$ & IMA/RCCA & $\begin{array}{c}\text { Retro- } \\
\text {-oesophageal }\end{array}$ & NRLN \\
\hline
\end{tabular}

*IMA is mentioned by authors as inferior thyroid artery; ${ }^{* *}$ According to Pratt's recognition of IMA [54], authors incorrectly describe their finding as being an inferior thyroid artery instead of an IMA; LCCA — left common carotid artery; RCCA — right common carotid artery; NRLN — non recurrent laryngeal nerve; RLN — recurrent laryngeal nerve; RVA — right vertebral artery

NRLN preservation is extremely challenging, even to experienced hands. To avoid nerve injury, a preoperative identification with computed tomography scan of the neck area and the intraoperative neuromonitoring has commonly been applied [28].

IMA supplies the thyroid gland when the superior and/or the inferior thyroid arteries are absent (3-6\%) or mal-developed or when the blood flow increases due to pathological conditions. The artery has a small calibre when passes to thymus (thymica accessoria) and although the gland is almost completely atrophied, total degeneration never occurs [54]. Sporadic reports exist as regards the coexistence of arteria lusoria and IMA with a variable course of the recurrent laryngeal nerve (Table 1).

Most documented cases of RERSA are clinically silent, due to the fact that the vessel does not form a complete vascular ring around oesophagus and trachea [14]. However when clinical manifestations occur, cardiac symptoms or silent ischaemia may appear [1] with prominent symptoms the progressive dysphagia and dyspnoea, particularly when the RERSA wall is calcified and the advanced atherosclerosis and hardening of the vessel compressing the oesophagus [34]. Persistent cough may be the main symptom due to the pulsatile action of the aberrant artery on the tracheal wall [57] or the compression exerted by an existing aneurysm on the adjacent structures. Dyspnoea, stridor, feeding difficulty, recurrent respiratory infections are the main symptoms in childhood, due to the vulnerable trachea, while dysphagia is the primary symptom in adults $[27,53,59,63]$. Clinicians should not forget that in paediatric population, serious respiratory discomfort may appear without dysphagia [36]. Feeding or swallowing difficulties in patients with Down syndrome should immediately raise the suspicion of a RERSA, although only $10-20 \%$ of them will develop dysphagia [56]. Patients with undetected arteria lusoria and prolonged nasogastric intubation may develop spontaneous oesophageal fistulisation, after the pulsatile arterial compression on the oesophageal wall. A limited necrosis may progressively appear on the lumen of both structures, in association with the rigid intubation catheter. Fistula formation is a rare fatal event. Since trans-oesophageal ultrasound is usually diagnostic, the long-term placement of nasogastric tube should precede in intensive care patients [24-26]. Other manifestations like aneurysm formation, acute ischaemia of the right upper limb may occasionally develop $[10,47]$. The RERSA is an incidental finding on imaging studies [20] that needs further examination based on plain chest roentgenogram [11, 71] and oesophagography findings [14]. Once the anomaly is diagnosed, the precise vascular anatomy and other associated cardiac defects are investigated with echocardiogram or trans-oesophageal echocardiography [46, 71]. Contrast enhanced computed tomography scan, magnetic resonance imaging or conventional angiography will provide further information about the type and extent of lesion, which is extremely helpful in preoperative planning $[8,30,47,59]$. In cases of RERSA, the barium swallow of the oesophagus is a very helpful diagnostic tool, which will reveal the typical impression defect, while endoscopically a pulsatile mass may be discovered [33]. Treatment is indicated especially in cases of paediatric dysphagia. Surgical repair is mandatory in aneurysm cases [59] 
in order to avoid further serious or even fatal complications [12]. A combined endovascular and surgical treatment was reported [38], while minimally invasive surgical and endovascular techniques have also been suggested as repair methods $[6,17]$. Davidian et al. [19] accomplished the first successful treatment of an RERSA aneurysm using a polytetrafluoroethylene covered stent graft. Shennib and Diethrich [60] introduced innovative hybrid approaches, but long term results are not yet available. New endovascular techniques without thoracotomy are very promising, especially in immunocompromised patients [62]. Head and neck surgeons should always keep in mind all possible vascular anomalies in the region, especially when performing tracheostomy, employing either the open or the closed percutaneous dilatation. An aberrant RSA may be encountered unexpectedly during the procedure [15].

\section{CONCLUSIONS}

Patients with vascular anomalies are at higher risk of iatrogenic injuries intraoperatively. Head and neck and thoracic surgeons, interventional radiologists and cardiologists should always be aware of all possible variations of the aortic arch in order to achieve the best possible and uneventful surgical outcome when dealing with thyroid gland diseases. General practitioners, paediatricians, gastroenterologists, should always keep in mind the possibility of a vascular anomaly when a patient is recurrently diagnosed with wheezing, upper respiratory tract infections, cough and failure to thrive.

\section{REFERENCES}

1. Abhaichand RK, Louvard Y, Gobeil JF, Loubeyre C, Lefevre T, Morice MC (2001) The problem of arteria lusoria in radial transradial coronary angiography and angioplasty. Catheter Cardiovasc Interv, 54: 196-201.

2. Adachi B (1928) Das Arteriensystem der Japaner. $1^{\text {st }}$ Ed. Vol. 1. Verlag der Kaiserlich-Japanischen Universitat, Kenyusha Press, Kyoto, pp. 29-41, 168-174.

3. Almenar-Garcia V, Terol FF, Correa-Lacarcel J, Lloret J, Robles J, Del Campo FS (2002) Retro-esophageal subclavian artery: a case report. Surg Radiol Anat, 24: 232-234.

4. Anson BJ, McVay CB (1971) Surgical anatomy. 5th Ed. W.B. Saunders, Philadelphia, London, Toronto, pp. 408-412.

5. Asherson N (1979) David Bayford. His syndrome and sign of dysphagia lusoria. Ann R Coll Surg Engl, 61: 63-67.

6. Attmann T, Brandt M, Müller-Hülsbeck S, Cremer J (2005) Two-stage surgical and endovascular treatment of an aneurysmal aberrant right subclavian (Lusoria) artery. Eur J Cardiothorac Surg, 27: 1125-1127.

7. Barry A (1951) The aortic arch derivatives in the human adult. Anat Rec, 111: 221-238.

8. Bensky A, O'Brien J, Hammon J (1995) Transesophageal echo probe compression of an aberrant right subclavian artery. J Am Society Echocardiogr, 8: 964-966.
9. Bergman RA, Afifi AK, Miyauchi R (1985-2002) Illustrated encyclopedia of human anatomicvariation. http://www.vh.org/ Providers/Textbooks/AnatomicVariants/Cardiovascular/Text/ Arteries/Aorta.html, pp. 1-35.

10. Boas N, Desmoucelle F, Bernadet V, Franceschi JC (2002) Rare cause of acute ischemia of the right upper extremity: thrombosis of a retroesophageal subclavian artery. Ann Vasc Surg, 16: 387-390.

11. Branscom JJ, Austin JH (1973) Aberrant right subclavian artery. Findings seen on plain chest roentgenograms. Am J Roentgenol Radium Ther Nucl Med, 119: 539-542.

12. Bull PG, Denck H (1994) Aberrant right subclavian artery. Eur J Vasc Surg, 8: 757-760.

13. Canty TG Jr, Boyle EM Jr, Linden B, Healey PJ, Tapper D, Hall DG, Sawin RS, Foker JE (1997) Aortic arch anomalies associated with long gap esophageal atresia and tracheoesophageal fistula. J Pediatr Surg, 32: 1587-1591.

14. Carrizo GJ, Marjani MA (2004) Dysphagia lusoria caused by an aberrant right subclavian artery. Tex Heart Inst J, 31: 168-171.

15. Chadha NK, Chiti-Batelli S (2004) Tracheostomy reveals a rare aberrant right subclavian artery; a case report. BMC Ear Nose Throat Disord, 4: 1-3.

16. Chaoui R, Heling KS, Sarioglu N, Schwabe M, Dankof A, Bollmann R (2005) Aberrant right subclavian artery as a new cardiac sign in second- and third-trimester fetuses with Down syndrome. Am J Obstet Gynecol, 192: 257-263.

17. Da Silva R. Anatomical study of the variation in the branching patterns and histology of the aorta in a South African population. Diss. University of Western Australia, Australia, 2012.

18. Daselar EH, Anson BJ (1959) Surgical anatomy of the subclavian artery and its branches. Surg Gynecol Obstet, 108: 149-174.

19. Davidian M, Kee ST, Kato N, Semba CP, Razavi MK, Mitchell RS, Dake A (1998) Aneurysm of an aberrant right subclavian artery: treatment with PTFE covered stentgraft. J Vasc Surg, 28: 335-339.

20. Davies M, Guest PJ (2003) Developmental abnormalities of the great vessels of the thorax and their embryological basis. Br J Radiol, 76: 491-502.

21. De Garis CF, African IH, Riemenschneider EA (1933) Patterns of the aortic arch in American Caucasian and Negro stocks, with comparative notes on certain other mammals. J Anat, 67:599-619.

22. Deveze A, Sebag F, Hubbard J, Jaunay M, Maweja S, Henry JF (2003) Identification of patients with a non-recurrent inferior laryngeal nerve by duplex ultrasound of the brachiocephalic artery. Surg Radiol Anat, 25:263-269.

23. Ellis H, Healy JC, Johnson D, Williams A eds. (2005) Forearm. In: Gray's anatomy: the anatomical basis of clinical practice. $39^{\text {th }}$ Ed. Churchill Livingstone, Edinburg, pp. 664, 873-883, 1021-1023.

24. Eynden FV, Devière J, Laureys M, Cannière D (2012) Erosion of a retroesophageal subclavian artery by an esophageal prosthesis. J Thorac Cardiovasc Surg, 144: 1183-1184.

25. Fazan VP, Ribeiro RA, Ribeiro JA, Filho OA (2003) Right retroesophageal subclavian artery. Acta Cirúrgica Brasileira, 18: 54-56.

26. Feugier $P$, Lemoine $L$, Gruner L, Bertin-Maghit M, Rousselet $B$, Chevalier JM (2003) Arterioesophageal fistula: a rare complication of retroesophageal subclavian arteries. Ann Vasc Surg, 17: 302-305.

27. Freed K, Low VH (1997) The aberrant subclavian artery. Am J Roentgenol, 168: 481-484.

28. Gao EL, Zou X, Zhou YH, Xie DH, Lan J, Guan HG (2014) Increased prediction of right nonrecurrent laryngeal nerve in thyroid surgery using preoperative computed tomography with intraoperative neuromonitoring identification. World J Surg Oncol, 12: 262.

29. Goldstein W (1965) Aberrant right subclavian artery in mongolism. Am J Roentgenol Radium Ther Nucl Med, 95: 131-134.

30. Gross RE (1946) Surgical treatment for dysphagia lusoria. Ann Surg, 124: 532-534.

31. Hammer DL, Meis A (1941) Thyroid arteries and anomalous subclavian in the whites and negro. Am J Phys Anthr, 28: 227-237. 
32. Henry JF, Audiffret J, Denizot A, Plan M (1988) The nonrecurrent inferior laryngeal nerve: review of 33 cases, including two on the left side. Surgery, 104: 977-984

33. Janssen M, Baggen MG, Veen HF, Smout AJ, Bekkers JA, Jonkman JG, Ouwendijk RJ (2000) Dysphagia lusoria: clinical aspects, manometric findings, diagnosis, and therapy. Am J Gastroenterol, 95: 1411-1416.

34. Jebara VA, Oussouldjogli E, Rassi I, Tabet G, Fabre-Bouabboud V (1995) Aberrant right subclavian artery aneurysm: a surgical review. Lebanese Med J, 43: 157-161.

35. Karacan A, Türkvatan A, Karacan K (2014) Anatomical variations of aortic arch branching: evaluation with computed tomographic angiography. Cardiol Young, 24: 485-493.

36. Klinkhamer AC (1966) Aberrant right subclavian artery clinical and roentgenologic aspects. Am J Roentgenol Radium Ther Nucl Med, 97: 438-446.

37. Krudy GA, Doppman $\sqcup$, Brennan FM (1980) The significance of the thyroidea ima artery in arteriographic localization of parathyroid adenomas. Radiology, 136: 51-55.

38. Lacroix V, Astarci P, Philippe D, Goffette P, Hammer F, Verhelst R, Noirhomme P (2003) Endovascular treatment of an aneurysmal aberrant right subclavian artery. J Endovasc Ther, 10: 190-194.

39. Lale P, Toprak U, Yagiz G, Kaya T, Uyanik SA (2015) Variations in the branching pattern of the aortic arch detected with computerized tomography angiography. Adv Radiol: 66: 44-52.

40. Levitt B, Richter JE (2007) Dysphagia lusoria: a comprehensive review. Dis Esophagus, 20: 455-460.

41. Lippert H, Pabst R (1985) Arterial variations in man. Classification and frequency. JF Bergmann Verlag, Munich, pp 4-6.

42. Loukas M, Louis RG Jr, Gaspard J, Fudalej M, Tubbs RS, Merbs W (2006) A retrotracheal right subclanian artery in association with a vertebral artery and thyroidea ima. Folia Morphol, 65: 236-241.

43. Mc Donald JJ, Anson BJ (1940) Variations in the origin of arteries derived from the aortic arch, in American Caucasians and Negroes. Am J Phys Anthropol, 27: 91-107.

44. Molz G, Burri B (1978) Aberrant subclavian artery (arteria lusoria): sex differences in the prevalence of various forms of the malformation. Evaluation of 1378 observations. Virchows Arch A Pathol Anat Histol, 380: 303-315.

45. Momma K, Matsuoka R, Takao A (1999) Aortic arch anomalies associated with chromosome 22q11 deletion (CATCH 22). Pediatr Cardiol, 20: 97-102.

46. Muhiudeen I, Silverman N (1993) Intraoperative transesophageal echocardiography using high resolution imaging in infants and children with congenital heart disease. Echocardiography, 10: 599-608.

47. Myers PO, Fasel JH, Kalangos A, Gailloud P (2010) Arteria lusoria: developmental anatomy, clinical, radiological and surgical aspects. Ann Cardiol Angiol, 59: 147-154.

48. Nakatani T, Tanaka S, Mizukami S (1998) Anomalous triad of a left sided inferior vena cava, a retroesophageal right subclavian artery, and bilateral superficial brachial arteries in one individual. Clin Anat, 11: 112-117.

49. Natsis K, Didagelos M, Manoli SM, Papathanasiou E, Sofidis G, Anastasopoulos N (2011) A bicarotid trunk in association with an aberrant right subclavian artery. Report of two cases, clinical impact, and review of the literature. Folia Morphol, 70: 68-73.

50. Natsis K, Tsitouridis I, Didagelos M, Fillipidis A, Vlasis K, Tsikaras P (2009) Anatomical variations in the branches of the human aortic arch in 633 angiographies: clinical significance and literature review. Surg Radiol Anat, 31: 319-323.

51. Nayak SR, Pai MM, Prabhu LV, D'Costa S, Shetty P (2006) Anatomical organization of aortic arch variations in the India: embryological basis and review. J Vasc Bras, 5: 95-100.

52. Nelson ML, Sparks CD (2001) Unusual aortic arch variations: distal origin of common carotid arteries. Clin Anat, 14: 62-65.

53. Polguj M, Chrzanowski L, Kasprzak JD, Stefanczyk L, Topol M, Majos A (2014) The aberrant right subclavian artery (arteria lusoria): the morphological and clinical aspects of one of the most important variations: a systematic study of 141 reports. Scientific World J, 2014: 292734.
54. Pratt GW (1916) The thyroidea ima artery. J Anat Physiol, 50: 239-242.

55. Reinshagen L, Vodiskar J, Mühler E, Hövels-Gürich $\mathrm{HH}$, Vazquez-Jimenez JF (2014) Bicarotid trunk: how much is "not uncommon"? Ann Thorac Surg, 97: 945-949.

56. Roofthooft MT, van Meer H, Rietman WG, Ebels T, Berger RM (2008) Down syndrome and aberrant right subclavian artery. Eur J Pediatr, 167: 1033-1036.

57. Rosa P, Gillespie DL, Goff JM, O'donnell SD, Starnes B (2003) Aberrant right subclavian artery syndrome: a case of chronic cough. J Vasc Surg, 37: 1318-1321.

58. Roszel A (1966) Uber die Anomalie der Arteria subclavian dextra und die Persistenz der Vena cava superior sinistra. Anat Anz, 188: 348-367.

59. Ruzmetov M, Vijay P, Rodefeld MD, Turrentine MW, Brown JW (2009) Follow-up of surgical correction of aortic arch anomalies causing tracheoesophageal compression: a 38-year single institution experience. J Pediatr Surg, 44: 1328-1332.

60. Shennib H, Diethrich EB (2008) Novel approaches for the treatment of the aberrant right subclavian artery and its aneurysms. J Vasc Surg, 47: 1066-1070.

61. Simmons JT, Doppman JL, Norton J (1987) Inferior thyroid artery arising from common carotid artery with aberrant right subclavian artery. Cardiovasc Intervent Radiol, 10: 150-152.

62. Simon RW, Lachat M, Pfammatter T, Amann-Vesti BR (2006) Giant aneurysm of an aberrant right subclavian artery from the left aortic arch. J Thorac Cardiovasc Surg, 132: 1478-1479.

63. Singh S, Grewal PD, Symons J, Ahmed A, Khosla S, Arora R (2008) Adult-onset dysphagia lusoria secondary to a dissecting aberrant right subclavian artery associated with type $B$ acute aortic dissection. Can J Cardiol, 24: 63-65.

64. Tartaglia F, Blasi S, Tromba L, Squeglia M, Russo G, Di Matteo FM, Carbotta G, Campana FP, Berni A (2011) Duplex ultrasound and magnetic resonance imaging of the supra-aortic arches in patients with non-recurrent inferior laryngeal nerve: a comparative study. G Chir, 32: 245-250.

65. Tateda M, Hasegawa J, Sagai S, Nakanome A, Katagiri K, Ishida E, Kanno R, Hasegawa T, Kubayashi T (2008) Nonreccurent inferior laryngeal nerve without vascular anomaly as a genuine entity. Tohoku J Exp Med, 216: 133-137.

66. Toniato A, Mazzarotto R, Piotto A, Bernante P, Pagetta C, Pelizzo MR (2004) Identification of the nonrecurrent laryngeal nerve during thyroid surgery: 20-year experience. World J Surg, 28: 659-661.

67. Toniato A, Merante Boschin I, Pagetta C, Casalide E, Pelizzo M (2010) A "Pilot light" of the right non-recurrent laryngeal nerve. Acta Otorhinolaryngol Ital, 30: 107-109.

68. Vucurevic G, Marinkovic S, Puskas L, Kovacevic I, Tanaskovic S, Radak D, Ilic A (2013) Anatomy and radiology of the variations of aortic arch branches in 1266 patients. Folia Morphol, 72: $113-122$.

69. Wang Z, Zhang H, Zhang P, He L, Dong W (2014) Preoperative diagnosis and intraoperative protection of nonrecurrent laryngeal nerve: a review of 5 cases. Med Sci Monit, 20: 233-237.

70. Williams D, Aff HM, Schmeceebier M, Edmonds HW (1932) Variations in the arrangement of the branches arising from the aortic arch in American whites and negroes. Anat Rec, 54: 247-251.

71. Woods RK, Sharp RJ, Holcomb GW 3rd, Snyder CL, Lofland GK, Ashcraft KW, Holder TM (2001) Vascular anomalies and tracheoesophageal compression: a single institution's 25-year experience. Ann Thorac Surg, 72: 434-438.

72. Yew KL (2014) Arteria lusoria and persistent left superior vena cava: vessel aberrancy is a bane for cardiologist too. Med J Malaysia, 69: 103.

73. Yilmaz E, Celik HH, Durgun B, Atasever A, llgi S (1993) Arteria thyroidea ima arising from the brachiocephalic trunk with bilateral absence of inferior thyroid arteries: a case report. Surg Radiol Anat, 15: 197-199.

74. Zapata H, Edwards EJ, Titus $\amalg$ (1993) Aberrant right subclavian artery with left aortic arch: associated cardiac anomalies. Pediatr Cardiol, 14: 159-161. 